\title{
Effectiveness and safety of PCSK9 inhibitor therapy in patients with familial hypercholesterolemia within a therapeutic program in Poland: Preliminary multicenter data
}

\author{
Krzysztof Chlebus ${ }^{1,2}$, Barbara Cybulska ${ }^{3}$, Piotr Dobrowolski ${ }^{4}$, \\ Marzena Romanowska-Kocejko ${ }^{2,5}$, Marta Żarczyńska-Buchowiecka ${ }^{2,5}$, \\ Natasza Gilis-Malinowska ${ }^{1,2}$, Aneta Stróżyk ${ }^{1,2}$, Justyna Borowiec-Wolna ${ }^{1,2}$, \\ Marcin Pajkowski ${ }^{2,5}$, Beata Bobrowska ${ }^{6,7}$, Renata Rajtar-Salwa ${ }^{6,7}$, \\ Aleksandra Kwapiszewska ${ }^{4}$, Małgorzata Waluś-Miarka ${ }^{6}$, Magdalena Chmara ${ }^{8,9}$, \\ Rafał Gałąska ${ }^{1}$, Maciej Małecki ${ }^{6}$, Tomasz Zdrojewski ${ }^{10}$, Marcin Gruchała ${ }^{1,2}$ \\ ${ }^{1} 1^{\text {st }}$ Department of Cardiology, Medical University of Gdansk, Poland \\ ${ }^{2}$ National Center for Familial Hypercholesterolemia, University Clinical Center, Gdansk, Poland \\ ${ }^{3}$ National Institute of Public Health - National Institute of Hygiene, Warsaw, Poland \\ ${ }^{4}$ Department of Hypertension, National Institute of Cardiology, Warsaw, Poland \\ ${ }^{5}$ Department of Cardiac Diagnostics, Medical University of Gdansk, Poland \\ ${ }^{6}$ Department of Metabolic Diseases, Jagiellonian University Medical College, Krakow, Poland \\ ${ }^{7}$ Department of Cardiology and Cardiovascular Interventions, University Hospital, Krakow, Poland \\ ${ }^{8}$ Department of Biology and Medical Genetics, Medical University of Gdansk, Poland \\ ${ }^{9}$ Laboratory of Clinical Genetics, University Clinical Center, Gdansk, Poland \\ ${ }^{10}$ Department of Preventive Medicine and Education, Medical University of Gdansk, Poland
}

\begin{abstract}
Background: In Poland, treatment with proprotein convertase subtilisin/kexin type 9 (PCSK9) inhibitors has become available free of charge in a therapeutic program. Assessed herein, is the efficacy and safety of alirocumab and evolocumab in patients with heterozygous familial hypercholesterolemia (FH). Methods: Data of 55 adult FH patients who participated in the program were analyzed upon meeting the criteria established by the Ministry of Health (low density lipoprotein cholesterol [LDL-C] above 160 $m g / d L$ on max. tolerated statin dose and ezetimib). The efficacy of PCSK9 inhibitors in reducing $L D L-C$ with drug administration every 2 weeks was assessed after 3 months and 1 year of therapy. A safety profile evaluation was performed at each visit. 48 patients completed the 3-month and 21 for the 1-year observation periods (34 patients treated with alirokumab and 14 with evolocumab).

Results: The mean concentration of direct-measured LDL-C decreased from the initial level of $215.1 \pm$ $\pm 74.5 \mathrm{mg} / \mathrm{dL}$ to $75.3 \pm 64.1 \mathrm{mg} / \mathrm{dL}$, i.e., by $65 \pm 14 \%$ following 3 months of treatment. This effect was stable in 1-year observation (77.7 $\pm 72.8 \mathrm{mg} / \mathrm{dL})$. Adverse effects were flu-like symptoms (13.0\%), injection site reactions (11.1\%), fatigue (5.6\%) and musculoskeletal symptoms (5.6\%). Seven patients failed to complete the 3-month treatment period due to side effects or non-compliance, and 1 patient failed to complete the 1-year treatment due to myalgia.
\end{abstract}

Address for correspondence: Krzysztof Chlebus, MD, PhD, $1^{\text {st }}$ Department of Cardiology, Medical University of Gdansk, ul. Dębinki 7, 80-211 Gdańsk, Poland, tel: +48 517304 377, e-mail: chlebus@gumed.edu.pl

Received: 13.10.2021 Accepted: 13.12.2021 Early publication date: 11.01.2022

This article is available in open access under Creative Common Attribution-Non-Commercial-No Derivatives 4.0 International (CC BY-NC-ND 4.0) license, allowing to download articles and share them with others as long as they credit the authors and the publisher, but without permission to change them in any way or use them commercially. 
Conclusions: This study confirmed high effectiveness of PCSK9 inhibitors in reducing LDL-C levels in patients with FH. Due to restrictive inclusion criteria with $L D L-C$ threshold level $>160 \mathrm{mg} / \mathrm{dL}$ $(>4.1 \mathrm{mmol} / \mathrm{L})$ required for participation in the therapeutic program, a relatively small number of $F H$ patients were eligible for treatment. (Cardiol J 2022; 29, 1: 62-71)

Key words: familial hypercholesterolemia, PCSK9 inhibitors, alirocumab, evolocumab, LDL-cholesterol reduction, clinical side effects

\section{Introduction}

Cardiovascular (CV) diseases (CVD) account for $46 \%$ of all deaths in Poland [1]. The low-density lipoprotein cholesterol (LDL-C) level is one of most important CVD risk factors and lowering this level remains a key point in CV risk reduction [2]. The intensity of hypolipemic therapy and LDL-C treatment goals varies depending on the $\mathrm{CV}$ risk category [3]. For people at very-high and high $(\mathrm{CV})$ risk LDL-C should be decreased $<55 \mathrm{mg} / \mathrm{dL}$ $(<1.4 \mathrm{mmol} / \mathrm{L})$ and $<70 \mathrm{mg} / \mathrm{dL}(<1.8 \mathrm{mmol} / \mathrm{L})$, respectively and reduced $\geq 50 \%$ from baseline. Individuals with familial hypercholesterolemia $(\mathrm{FH})$ and atherosclerotic CVD or other major risk factors, are at very-high CV risk, but those without other major risk factors are at high risk. $\mathrm{FH}$ is a quite common genetic disorder with a prevalence of approximately 1 in 250 adults in Poland [4]. It is estimated that the disease affects over 136,000 adults [5]. The prevalence of FH in the Polish population is very similar to the recent worldwide data (1 in 311-313 individuals) [6, 7]. However, FH remains underdiagnosed and undertreated, and many patients fail to achieve the target LDL-C level despite intensive statin therapy even in combination with ezetimibe $[5,8]$. In such situations the new therapeutic strategy may be the addition of proprotein convertase subtilisin/kexin type 9 (PCSK9) inhibitors [2]. It has been shown that PCSK9 inhibitors (evolocumab and alirocumab) reduce LDL-C level on average by $60 \%[9,10]$. According to 2019 European Society of Cardiology/European Society of Atherosclerosis (2019 ESC/EAS) guidelines for the management of dyslipidemias PCSK9 inhibitors are recommended in very-high risk patients with $\mathrm{FH}$ if the treatment goal is not achieved on maximal tolerated statin with ezetimibe. PCSK9 inhibitors are also recommended in $\mathrm{FH}$ patients who do not tolerate statins [3]. In contrary to recent ESC/EAS guidelines, a Polish group of experts, in a statement from 2016, recommended PCSK9 inhibitors implementation in patients with heterozygous $\mathrm{FH}(\mathrm{HeFH})$ if LDL-C levels are above $160 \mathrm{mg} / \mathrm{dL}$ $(4.1 \mathrm{mmol} / \mathrm{L})$ on high-intensity statin treatment (atorvastatin $40-80 \mathrm{mg} / \mathrm{d}$ or rosuvastatin 20 $-40 \mathrm{mg} / \mathrm{d}$ ) [11]. This statement was considered by the Polish Ministry of Health when defining criteria of a new PCSK9 therapeutic program for patients with $\mathrm{FH}$ that is currently financed by the National Health Found.

The aim of the current observational study was to assess PCSK9 inhibitors efficacy and safety among Polish FH patients participating in a drug/ /therapeutic program for patients with $\mathrm{FH}$.

\section{Methods}

Fifty-five adult patients with FH and LDL-C levels $>160 \mathrm{mg} / \mathrm{dL}(>4.1 \mathrm{mmol} / \mathrm{L})$ were qualified for the drug program with alirocumab or evolocumab (from March 2019 to January 2021) under the National Center for Familial Hypercholesterolemia (Gdansk), The National Institute of Cardiology (Warsaw) and University Hospital (Krakow). 43 patients were receiving high-intensity statin treatment for at least 6 months, and 10 patients were on the maximum tolerated dose of a statin, 2 patients did not use statin due to total intolerance. Rosuvastatin was taken in dose $40 \mathrm{mg}$ per day by 32 patients, $20 \mathrm{mg}$ by 3 patients, lower doses 5 patients $(15 \mathrm{mg}-1$ patient, $5 \mathrm{mg}-2$ patients, $<5 \mathrm{mg}$ per day -2 patients). Atorvastatin was taken in doses of $80 \mathrm{mg}$ per day by 3 patients, $60 \mathrm{mg}$ by 1 patient, $40 \mathrm{mg}$ by 4 patients, $20 \mathrm{mg}$ by 1 patient, $10 \mathrm{mg}$ by 2 patients, lower doses than $10 \mathrm{mg} /$ day by 2 patients. Three patients did not use ezetymibe. Two of them were patients with statin intolerance (one did not use statin, one used atorvastatin in a dose of $<10 \mathrm{mg}$ per day). One patient was on high-intensity statin - rosuvastatin $20 \mathrm{mg}$. Intolerance to standard therapy has always been reliably confirmed by the patient's physician (general practitioner or cardiologist). The described baseline hypolipemic therapy was not altered during the trial. All patients received alirocumab or evolocumab subcutaneously every 2 weeks at a dose of $150 \mathrm{mg}$ or $140 \mathrm{mg}$, respectively. The evaluation of the treatment effectiveness was assessed after 2 and 4 weeks and obligatorily after 
Table 1. Characteristics of patients prior to study entry $(n=55)$.

\begin{tabular}{|c|c|c|}
\hline Characteristic & Mean (SD) or $n(\%)$ & Median (IQR) \\
\hline Age (years) & $54.8(11.1)$ & $54.0(47.5-61)$ \\
\hline Female $(n, \%)$ & $26(47.3)$ & \\
\hline BMI $\left[\mathrm{kg} / \mathrm{m}^{2}\right]$ & $28.5(4.4)$ & $28.0(25.0-31.8)$ \\
\hline Waist ( $n=32$ ) & $97.9(12.4)$ & $95.5(89.0-104.8)$ \\
\hline $\mathrm{SBP}[\mathrm{mmHg}]$ & $134.5(14.4)$ & $134.0(127.0-142.4)$ \\
\hline $\mathrm{DBP}[\mathrm{mmHg}]$ & $82.7(9.6)$ & $82.0(75.0-88.0)$ \\
\hline $\mathrm{HR} / \min (\mathrm{n}=51)$ & $70.7(9.0)$ & $70.0(65.0-75.5)$ \\
\hline $\mathrm{TC}[\mathrm{mg} / \mathrm{dL}]$ & $314.0(83.3)$ & $294.0(244.5-357.5)$ \\
\hline LDL-C [mg/dL] (direct) $(n=50)$ & $237.4(80.1)$ & $209.0(180.5-267.8)$ \\
\hline LDL-C [mg/dL] (calculated) & $224.1(79.1)$ & $192.0(173.2-255.0)$ \\
\hline $\mathrm{HDL}[\mathrm{mg} / \mathrm{dL}]$ & $47.9(14.7)$ & $48.0(38.0-55.5)$ \\
\hline $\mathrm{TG}[\mathrm{mg} / \mathrm{dL}]$ & $211.2(154.5)$ & $154.0(130.0-231.0)$ \\
\hline apo $B[g / d L](n=32)$ & $1.7(0.5)$ & $1.6(1.3-1.9)$ \\
\hline $\operatorname{Lp}(a)[g / d L](n=44)$ & $0.7(0.7)$ & $0.3(0.2-1.0)$ \\
\hline Glucose $[\mathrm{mg} / \mathrm{dL}](\mathrm{n}=48)$ & $100.3(21.6)$ & $94.5(86.0-108.5)$ \\
\hline Creatinine $[\mathrm{mg} / \mathrm{dL}]$ & $0.9(0.2)$ & $0.8(0.8-1.0)$ \\
\hline GFR $[\mathrm{mL} / \mathrm{min}](\mathrm{n}=48)$ & $80.7(13.3)$ & $90.0(75.3-90.0)$ \\
\hline $\operatorname{ALT}[U / L](n=54)$ & $34.4(23.1)$ & $28.5(21.0-42.0)$ \\
\hline AST [U/L] $(n=45)$ & $26.3(10.1)$ & $25.0(19.0-31.0)$ \\
\hline CK $[U / L](n=54)$ & $153.0(113.7)$ & $126.0(69.3-192.8)$ \\
\hline CRP $[g / L](n=32)$ & $2.6(2.6)$ & $1.5(0.7-3.7)$ \\
\hline $\mathrm{TSH}[\mu \mathrm{U} / \mathrm{mL}](\mathrm{n}=49)$ & $1.2(0.9)$ & $1.1(0.7-1.6)$ \\
\hline
\end{tabular}

$\mathrm{ALT}$ - alanine aminotransferase; apo B — apolipoprotein B; AST — aspargine aminotransferase; BMI — body mass index; CK — creatine kinase; CRP — C-reactive protein; DBP — diastolic blood pressure; GFR - glomerular filtration rate; HbA1c - glycated hemoglobin; HDL-C — high density lipoprotein cholesterol; HR - heart rate; IQR - interquartile range; LDL-C - low density lipoprotein cholesterol; Lp(a) - lipoprotein (a); SBP — systolic blood pressure; SD - standard deviation; TC - total cholesterol; TG — triglycerides; TSH - thyreotropic hormone

3 months and 1 year of therapy. The safety of the therapy was assessed at each visit.

LDL-C concentrations were calculated both from Friedewald's formula and was determined using the direct method. Hospital medical records were used for demographic and clinical characteristics of patients.

This retrospective study was based on analysis of medical records of all consecutive patients enrolled to therapeutic program. All subjects included into the program were informed about the purpose of the program and signed informed consent. The conducted data analysis and therapeutic program were approved by Ministry of Health and strictly followed binding requirements.

\section{Statistical analysis}

Continuous data were presented as a mean value and standard deviation (SD), as well as a median and interquartile range (IQR). Categorical data were presented as a number and percentages.
Continuous paired data were compared by the Wilcoxon test and independent data were compared by the Mann-Whitney U test. $\mathrm{P}$ value of less than 0.05 was considered statistically significant. Data was analyzed using the R software v. 3.6.3.

\section{Results}

Demographic and baseline characteristics of patients are summarized in Table 1 . FH was diagnosed in patients with $>8$ points according to Dutch Lipid Clinic Network (DLCN) criteria; Median DLCN score was $12.0(10.0-15.0)$ points without genetic testing and $18(14.0-19.0)$ points with performed genetic results. Figure 1 presents the prevalence of individual criteria for the diagnosis of FH in the study participants. 36 out of 55 patients were diagnosed with genetic variant responsible for $\mathrm{FH}: 91.6 \%$ in the LDL $(\mathrm{n}=33)$ receptor (LDLR) gene and $2.4 \%(\mathrm{n}=3)$ in the apolipoprotein $\mathrm{B}$ (APOB) gene. In the remaining 


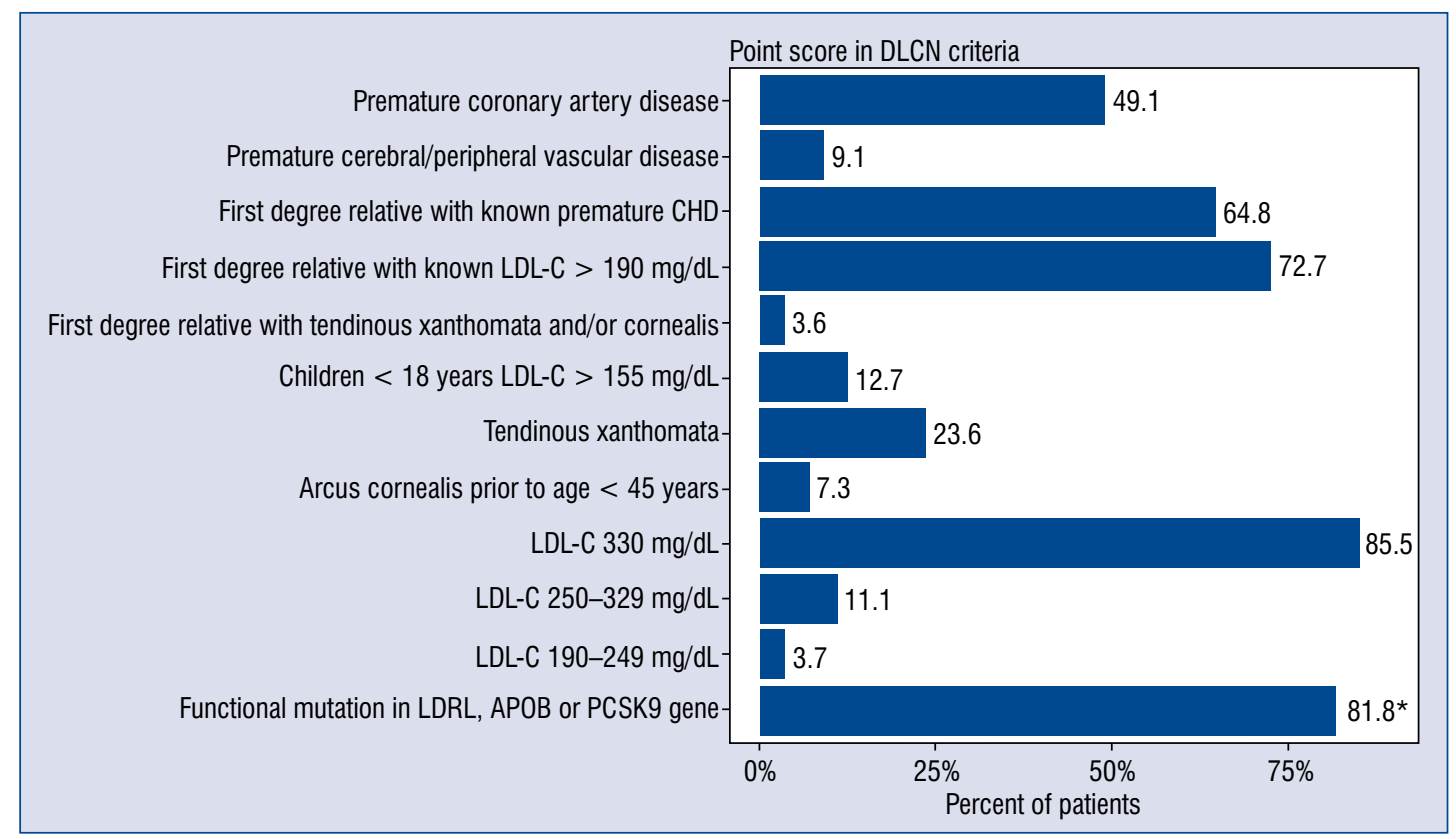

Figure 1. The prevalence of Dutch Lipid Clinic Network (DLCN) familial hypercholesterolemia criteria (point score) in patients under study; *Among patients referred to genetic testing; abbreviations - see text.

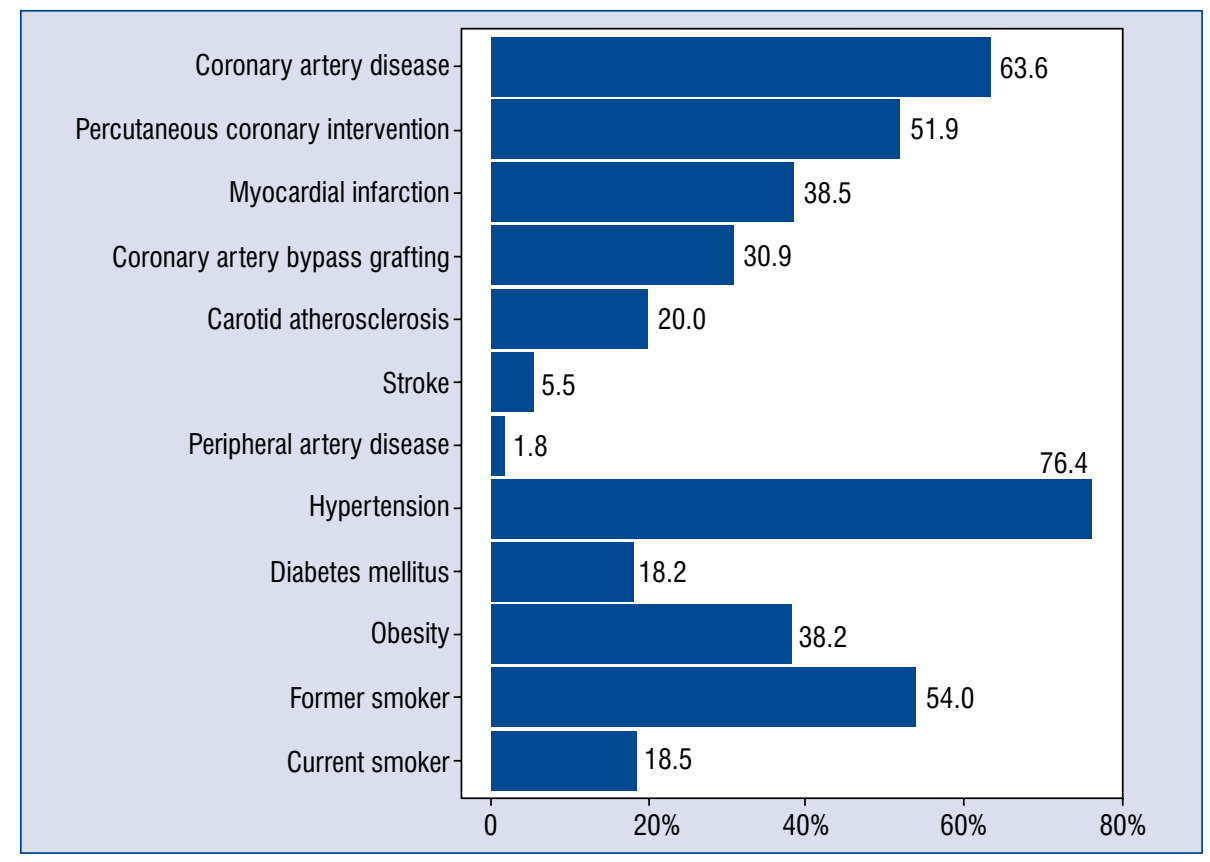

Figure 2. The prevalence of selected cardiovascular diseases, end-points and risk factors in familial hypercholesterolemia patients.

cases the causing mutation was not found $(\mathrm{n}=8)$ or genetic test was not performed $(n=11) .71 .4 \%$ of patients had a family history of hypercholesterolemia. $63.6 \%$ of patients had already established coronary artery disease (CAD), $49.1 \%$ had premature CAD, 20\% were diagnosed with carotid atherosclerosis and $5.5 \%$ with stroke (Fig. 2). Among the assessed risk factors, arterial hypertension was the most common (76.4\%). $38.2 \%$ of patients were diagnosed with obesity and $18.2 \%$ 
Table 2. Effects of proprotein convertase subtilisin/kexin type 9 (PCSK9) inhibitors on low density lipoprotein-cholesterol (LDL-C) level after 3 months therapy as added to statin and ezetymibe in familial hypercholesterolemia patients and baseline LDL-C > $160 \mathrm{mg} / \mathrm{dL}(>4.1 \mathrm{mmol} / \mathrm{L})(\mathrm{n}=48)$.

\begin{tabular}{lcccc}
\hline \multirow{2}{*}{ Lipid } & \multicolumn{2}{c}{ Mean (SD) } & P & $\begin{array}{c}\text { Reduction }(\%) / \\
\text { /Increase (\%) }\end{array}$ \\
\cline { 2 - 3 } & Before & After (3 months) & & $65.0(14.0)$ \\
\hline LDL-C $[\mathrm{mg} / \mathrm{dL}]$ (calculated) & $215.1(74.5)$ & $75.3(64.1)$ & $<0.001$ & $64.0(18.0)$ \\
LDL-C [mg/dL] (direct measurement) & $228.2(76.2)$ & $82.1(62.5)$ & $<0.001$ & $28.0(31.5)$ \\
Triglycerides [mg/dL] & $222.2(161.7)$ & $160.0(110.8)$ & $<0.001$ & $9.7(6.0)$ \\
HDL-C $[\mathrm{mg} / \mathrm{dL}]$ & $47.2(15.1)$ & $51.8(16.0)$ & 0.003 & $59.0(14.2)$ \\
Non-HDL-C [mg/dL] & $259.3(80.8)$ & $106.3(69.3)$ & $<0.001$ & \\
\hline
\end{tabular}

HDL-C — high density lipoprotein-cholesterol; SD — standard deviation

had diabetes. The mean LDL-C (Friedewald formula) before administration of PCSK9 inhibitors was $224.1(79.1) \mathrm{mg} / \mathrm{dL}$ and the median was 192.0 (173.2-255.0) $\mathrm{mg} / \mathrm{dL}$, and adequate for the direct method 237.4 (80.1) $\mathrm{mg} / \mathrm{dL}$ and 209.0 (180.5-267.8) $\mathrm{mg} / \mathrm{dL}$, respectively. The mean concentration of triglycerides was $211.2(154.5) \mathrm{mg} / \mathrm{dL}$, and the median was $154.0(130.0-231.0) \mathrm{mg} / \mathrm{dL}$ while high density lipoprotein cholesterol (HDL-C) was 47.9 (14.7) $\mathrm{mg} / \mathrm{dL}$ and 48.0 (38.0-55.5), respectively. In addition to lipid-lowering therapy, 38 patients were on angiotensin converting enzyme inhibitors or angiotensin-II-receptor antagonists, 36 on beta-blockers and 34 on acetylsalicylic acid; 11 patients were treated with a P2Y12 inhibitor.

The effectiveness of treatment was assessed after 3 months in 48 patients, 7 patients could not be tested after this obligatory period as they did not complete the study. Mean lipid levels before and after treatment and the mean reduction are presented in Table 2, while Figure 3 presents the effects of PCSK9 inhibitors on LDL-C levels in individual patients. Figure 4 presents the concentration of LDL-C after 2 and 4 weeks and after 3 months of therapy. As shown in Table 2, after 3 months of treatment with PCSK9 inhibitors, the mean calculated LDL-C concentration decreased significantly from $215.1 \pm 74.5 \mathrm{mg} / \mathrm{dL}$ to $75.3 \pm$ $\pm 64.1 \mathrm{mg} / \mathrm{dL}$, i.e., by $65.0 \pm 14.0 \%(\mathrm{p}<0.001)$, and when measured directly decreased from the $228.2 \pm 76.2 \mathrm{mg} / \mathrm{dL}$ to $82.1 \pm 62.5 \mathrm{mg} / \mathrm{dL}$, i.e., by $64.0 \pm 18.0 \%(\mathrm{p}<0.001)$. The median calculated LDL-C decreased from $187.0 \mathrm{mg} / \mathrm{dL}$ (171.5-241.3) to $64.8 \mathrm{mg} / \mathrm{dL}$ (37.7-86.2), i.e., by $70.9 \%$ (54.1-79.9 ), and measured directly from $204.5 \mathrm{mg} / \mathrm{dL}$ (178.8-262.5) to $71.5 \mathrm{mg} / \mathrm{dL}$ (43.5-93.5), i.e., by $68.2 \%$ (53.8-79.4). Therapeutic target was deemed achieved when at least one LDL-C result (calculated or directly determined) was $<55 \mathrm{mg} / \mathrm{dL}$
$(<1.4 \mathrm{mmol} / \mathrm{L})$ or $<70 \mathrm{mg} / \mathrm{dL}(<1.8 \mathrm{mmol} / \mathrm{L})$ for very-high and high $\mathrm{CV}$ risk patients, respectively. $25(52 \%)$ patients out of 48 achieved the therapeutic target, including 16 patients reaching levels below $55 \mathrm{mg} / \mathrm{dL}$ and 9 patients below $70 \mathrm{mg} / \mathrm{dL}$ (Fig. 3). The individual response to treatment with PCSK9 inhibitors was varied and ranged from $30.2 \%$ to $90 \%$ of LDL-C decrease. As presented in Figure 4, the greatest therapeutic effect was achieved after 2 weeks (following the first dose of drug), and the difference in the result after 4 weeks and 3 months, was insignificant in relation to the effect after 2 weeks. In Figure 5 we see the threshold values for LDL-C concentration (> $160 \mathrm{mg} / \mathrm{dL}$ ) making patients with $\mathrm{FH}$ eligible for the drug program with alirocumab and evolocumab compared with the thresholds recommended by 2017 ESC Task Group Guidelines [12]. Figure 5 also presents LDL-C levels before and after 3 months of treatment with PCSK9 inhibitors. The largest reduction in LDL-C occurred after the first drug administration, amounting to an average of $56.6 \%$. Patients on the maximum tolerated dose of statins $(n=11)$ had significantly higher initial mean LDL-C levels than patients on intensive statin therapy $(\mathrm{n}=37)$, i.e. calculated LDL-C of $253.7 \pm 91.7 \mathrm{mg} / \mathrm{dL}$ and that directly measured of $264.7 \pm 95.7 \mathrm{mg} / \mathrm{dL}$ vs. $203.7 \pm$ $\pm 65.7 \mathrm{mg} / \mathrm{dL}$ and $217.4 \pm 67.1 \mathrm{mg} / \mathrm{dL}(\mathrm{p}=0.008$ and $\mathrm{p}=0.04$, respectively). Following 3 months of PCSK9 inhibitors therapy, the concentration of LDL-C in the group treated with the maximum tolerated dose of statin was significantly higher than in the high intensity therapy group, with calculated levels of $110.3 \pm 75.6 \mathrm{mg} / \mathrm{dL}$ vs. $64.9 \pm 57.3 \mathrm{mg} /$ $/ \mathrm{dL}$ and when measured directly $118.6 \pm 74.6 \mathrm{mg} /$ $/ \mathrm{dL}$ vs. $71.2 \pm 55.0 \mathrm{mg} / \mathrm{dL}$ (both $\mathrm{p}=0.002$ ). Table 3 presents adverse effects that occurred during treatment. These included mainly flu-like symptoms $(\mathrm{n}=7,13 \%)$ and injection site reactions $(\mathrm{n}=6,11 \%)$. 


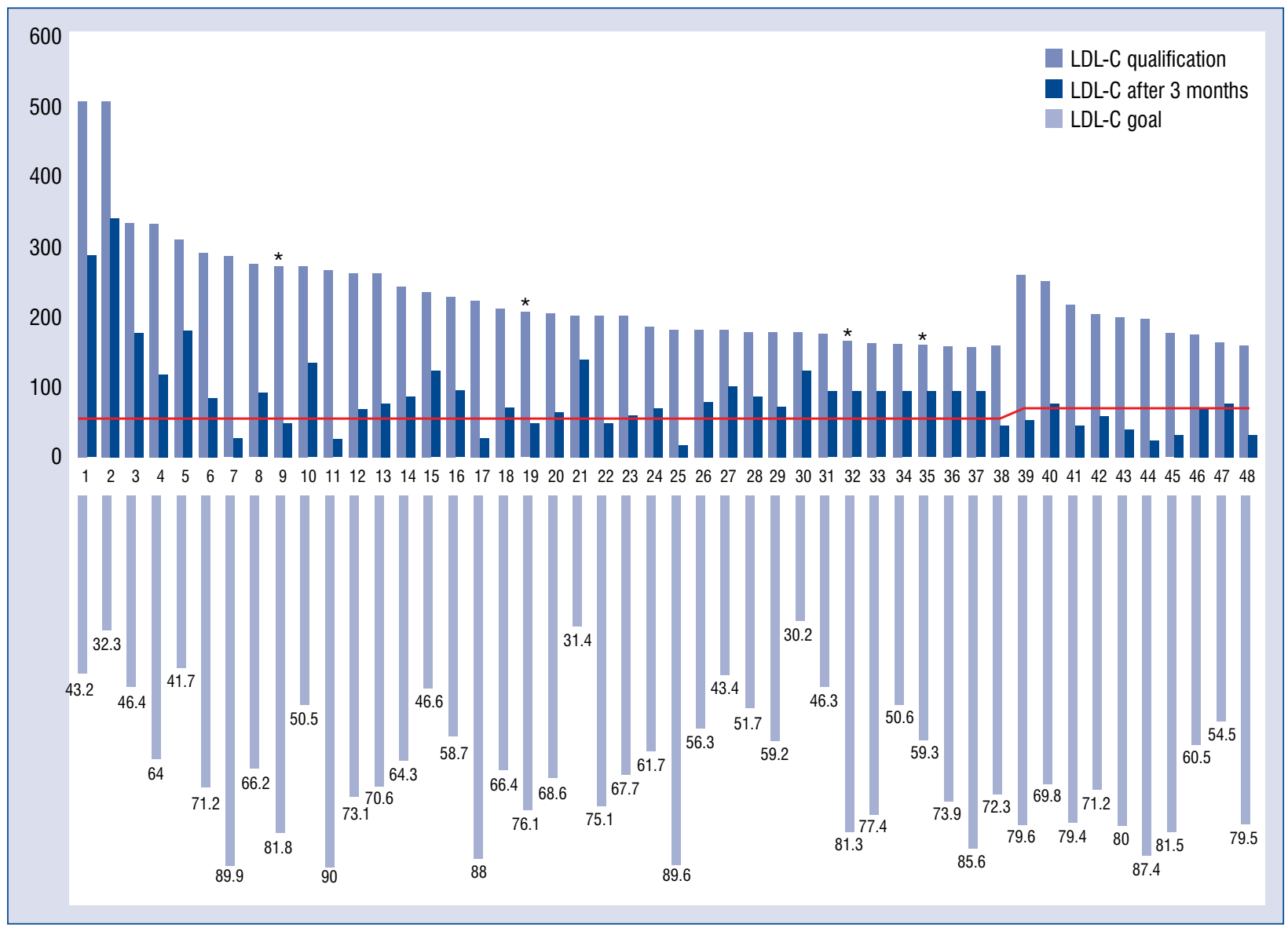

Figure 3. Effect of proprotein convertase subtilisin/kexin type 9 (PCSK9) inhibitors on low density lipoprotein-cholesterol (LDL-C) concentration and percent reduction in individuals after 3 months of therapy. The red line denotes the treatment goals for LDL-C concentrations of $<55 \mathrm{mg} / \mathrm{dL}(<1.4 \mathrm{mmol} / \mathrm{L})$ and $<70 \mathrm{mg} / \mathrm{dL}(<1.8 \mathrm{mmol} / \mathrm{L})$; black asterisk — no data of direct LDL-C (taken calculated LDL-C).

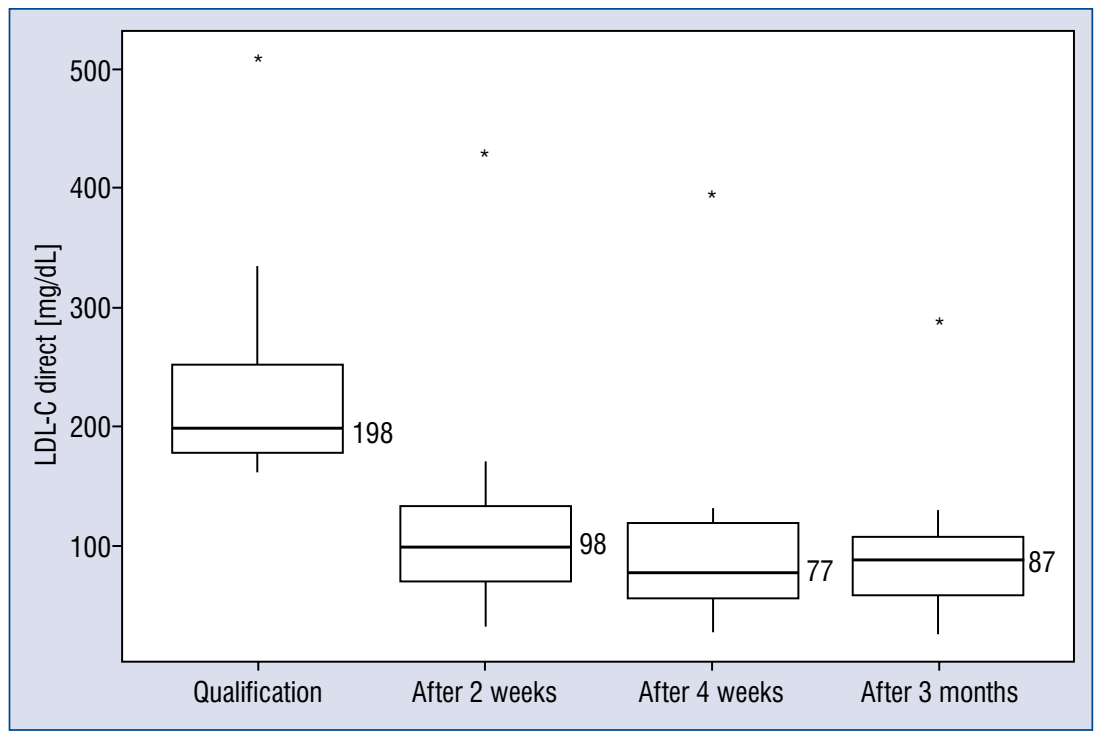

Figure 4. Low density lipoprotein-cholesterol (LDL-C) before and after 2 and 4 weeks and 3 months of treatment with proprotein convertase subtilisin/kexin type 9 (PCSK9) inhibitors. 


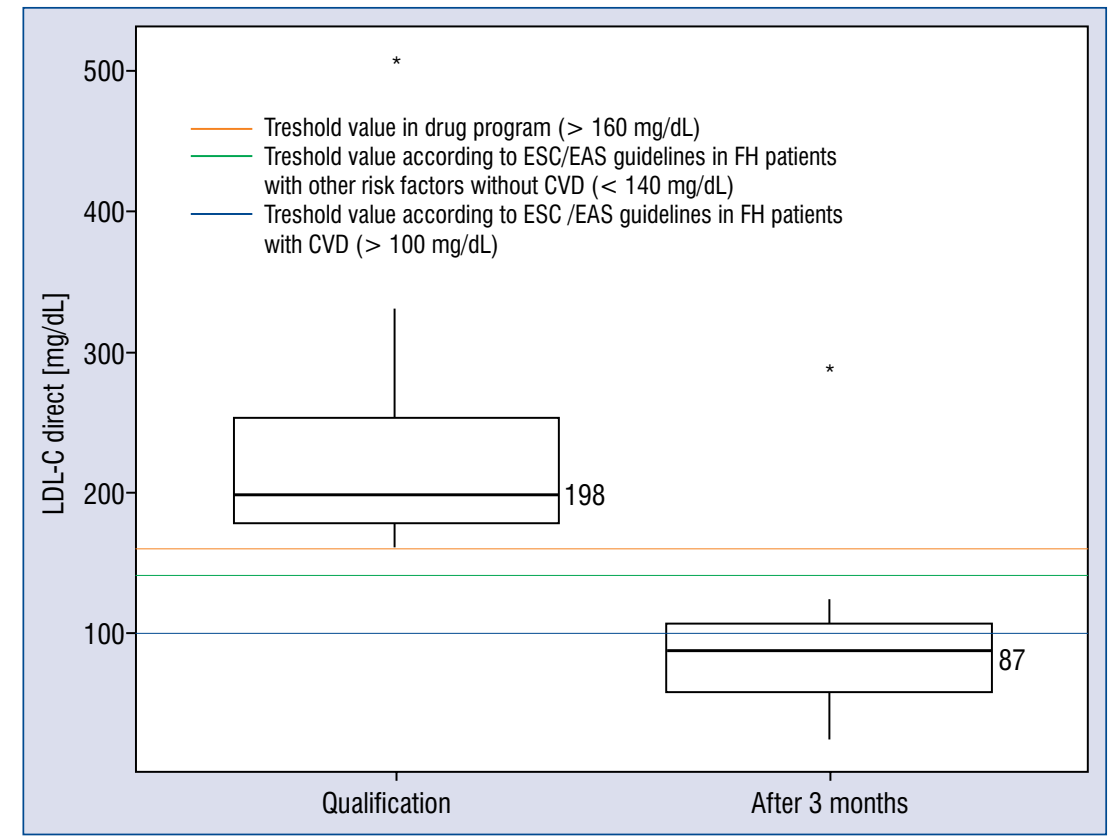

Figure 5. Low density lipoprotein-cholesterol (LDL-C) before and after 3 months of treatment with proprotein convertase subtilisin/kexin type 9 (PCSK9) inhibitors and threshold values propose for starting PCSK9 inhibitor therapy; CVD - cardiovascular disease; ESC/EAS - European Society of Cardiology/European Society of Atherosclerosis; $\mathrm{FH}$ - familial hypercholesterolemia.

Table 3. Number of patients who reported, at least once, the respective adverse effect $(100 \%$ represents 55 patients included in the treatment).

\begin{tabular}{lc}
\hline Side reaction & $\mathbf{N}(\%)$ \\
\hline Flu-like symptom & $7(13.0 \%)$ \\
Injections site reactions & $6(11.1 \%)$ \\
Fatigue & $3(5.6 \%)$ \\
Musculoskeletal symptoms & $3(5.6 \%)$ \\
Nasopharyngitis & $1(1.9 \%)$ \\
Gastrointestinal symptoms & $1(1.9 \%)$ \\
Erectile dysfunction & $1(1.9 \%)$ \\
Hot flashes & $1(1.9 \%)$ \\
Allergic reaction & $3(5.5 \%)$ \\
Discontinuation because of side effects & $4(7.4 \%)$ \\
Others & $2(3.6 \%)$ \\
All discontinuation & $8(14.5 \%)$ \\
\hline
\end{tabular}

Side effects were the cause of drug discontinuation in 3 patients in 3-month follow-up and in 1 patient in a 1-year follow-up (2 allergic reactions, problems with blood pressure fluctuation and myalgia). Two patients did not achieve a $30 \%$ reduction of LDL-C and 2 patients discontinued the drugs because of non-compliance. No CV events were observed during the observation period.

\section{Discussion}

Here, for the first time, real-world data on the effectiveness and safety of PCSK9 inhibitor therapy is presented in patients with FH from Poland.

The addition of PCSK9 inhibitors to lipid-lowering therapy (statin \pm ezetimibe) represents progress in therapeutic efforts to reach the recommended LDL-C levels. This is particularly important in patients with $\mathrm{FH}$, who are at a higher risk of premature CVD due to their high cholesterol exposure lasting from birth [13]. Despite being treated with the maximum or maximum tolerated dose of statin plus ezetimibe, $\mathrm{FH}$ patients still presented LDL-C concentrations far from the target value. The requirements for the inclusion criteria for the PCSK9 inhibitors drug program regarding the concentration of LDL-C are very strict, i.e. LDL-C > $160 \mathrm{mg} / \mathrm{dL}$. Even among patients treated at National Center for Familial Hypercholesterolemia with the molecular test as the standard diagnostic method and highest number of genetically confirmed patients, only $7.6 \%$ of probands with definite diagnosis and $4.7 \%$ of all patients with $\mathrm{FH}$ (probands and family members) met the conditions for participation in the program. This baseline LDL-C criterion influenced the study results, as only 25 from 48 of patients 
(52\%) achieved the LDL-C goal, 16 patients $<55$ $\mathrm{mg} / \mathrm{dL}(<1.4 \mathrm{mmol} / \mathrm{L})$ and 9 patients $<70 \mathrm{mg} / \mathrm{dL}$ $(<1.8 \mathrm{mmol} / \mathrm{L})$. According to the European guidelines for the management of dyslipidemia [3], it is recommended for patients with $\mathrm{FH}$ in secondary prevention to achieve LDL-C of $<55 \mathrm{mg} / \mathrm{dL}(<1.4$ $\mathrm{mmol} / \mathrm{l}$ ) (IC). The same therapeutic target should also be considered in $\mathrm{FH}$ patients in primary prevention in the presence of another additional major risk factor [3]. Other patients with $\mathrm{FH}$ are high $\mathrm{CV}$ risk patients with the recommended LDL-C target value of $<70 \mathrm{mg} / \mathrm{dL}(<1.8 \mathrm{mmol} / \mathrm{L})$. European experts recommend adding a PCSK9 inhibitor to therapy with the maximum tolerated dose of statin and ezetimibe in $\mathrm{FH}$ patients with a very high risk whenever the LDL-C levels are above the target value [3].

Treatment of $\mathrm{FH}$ patients with alirocumab and evolocumab was assessed in the placebo-controlled ODYSSEY FH I and II [14], in the ODYSSEY HIGH FH [15] and in the RUTHEFORD [16] clinical trials. Compared to the present cohort, a clear difference between the studies appeared in the diagnosis of FH. In the ODYSSEY trials, a different percentage of patients had genetic confirmation of the $\mathrm{FH}$ diagnosis, i.e., $39.9 \%$ (FH I), $70.1 \%$ (FH II) and $17.8 \%$ (HIGH FH), compared to $60 \%$ in the current work. There were also differences in the incidence of coronary heart disease. In the clinical trials the percentages were $45.5 \%, 34.7 \%$, and $43.1 \%$ in the alirocumab arm, respectively, while in the drug program it was $63.6 \%$. In ODYSSEY FH I and FH II, the mean baseline LDL-C concentration at the maximum tolerated dose of statin \pm other lipid-lowering drug was $144.7 \mathrm{mg} / \mathrm{dL}$ and 134.6 $\mathrm{mg} / \mathrm{dL}$, respectively, so it was lower than in the drug program and it decreased after 24 weeks of treatment in FH I to $71.3 \mathrm{mg} / \mathrm{dL}$ (on average by $57.9 \%$, placebo corrected), in FH II to $67.7 \mathrm{mg} / \mathrm{dL}$ (on average by $51.4 \%$, placebo corrected) [14], while after 12 weeks in the drug program to 82.1 $\mathrm{mg} / \mathrm{dL}$ (direct measurement), i.e., by an average of $65.0 \%$ and up to $75.3 \mathrm{mg} / \mathrm{dL}$ (LDL-C calculated), i.e., by an average of $64.0 \%$ (Table 2 ). LDL-C levels of $<70 \mathrm{mg} / \mathrm{dL}(<1.8 \mathrm{mmol} / \mathrm{L})$ were achieved by $59.8 \%$ of patients in $\mathrm{FH} \mathrm{I}$ and $68.2 \%$ of patients in FH II, however the baseline LDL-C was lower and the therapeutic targets were milder to be achieved. Patients with LDL-C concentrations of over $160 \mathrm{mg} / \mathrm{dL}$, similar to the present research, were included in the ODYSSEY HIGH FH [15]. The patients in the current study had to additionally be on ezetimibe for at least 1 month, but in ODYSSEY HIGH FH there was no such requirement. Mean LDL-C levels in those treated with alirocumab for over 24 weeks decreased from $196.3 \mathrm{mg} / \mathrm{dL}$ to 107 $\mathrm{mg} / \mathrm{dL}$, i.e. by $45.7 \%$, and $32 \%$ of patients reached LDL-C levels lower than $70 \mathrm{mg} / \mathrm{dL}$. In the present study, the reduction in LDL-C was greater and the lower values were achieved after 12 weeks of treatment. It is also true if the present results are compared with the RUTHERFORD trial, where patients receiving evolocumab plus standard of care experienced a mean $53.6 \%$ reduction LDL-C after 48 weeks [16].

Data on the use of PCSK9 inhibitors in clinical practice is limited, and the groups investigated so far were small - from 38 to 271 patients. The eligibility criteria for reimbursed treatment differ depending on the country, local epidemiological conditions and the budgetary capacity of the system. Depending on the $\mathrm{CV}$ risk and comorbidities, patients with LDL-C levels of 70-190 mg/dL were qualified for treatment [17-23]. Among the available publications, only one cohort described only patients with $\mathrm{FH}$ [21], in the remaining cases the percentage of these patients amounted to 51.5$-89.0 \%$. The studied populations were very similar in terms of their age - the average was 55-62 years, similar to the cohort in the present study. The incidence of CV diseases was 37.0-75.2\%. $94.7 \%$ in the German study, which included patients with atherosclerotic plaques in the carotid arteries and in the aorta [16], whereas the incidence of CAD in the Polish program was $63.6 \%$. Compared to other publications, hypertension was more common in the Polish population $-76.4 \%$ vs. $30.5-63.0 \%$, and the incidence of diabetes was higher in only 1 case - in the Israeli study [23] $31 \%$, in Poland this percentage amounted to $18.2 \%$. It is worth mentioning the recently published open-label ODYSSEY APPRISE trial with only one arm, i.e. patients treated with alirocumab without placebo [24]. This real-world setting study included 636 patients with $\mathrm{HeFH}$ and 358 patients without $\mathrm{FH}$, who were treated with alirocumab at doses of 75-150 mg every 2 weeks. Statins were taken by $87 \%$ of patients with $\mathrm{FH}$ and $56.7 \%$ of those without $\mathrm{FH}$. The proportions of patients taking ezetimibe were $69.3 \%$ and $41.3 \%$, respectively. In patients with $\mathrm{FH}$, the mean baseline LDL-C decreased from $196.3 \mathrm{mg} / \mathrm{dL}$ by $53.4 \%$ after 12 weeks of treatment with alirocumab, and in patients without $\mathrm{FH}$ from $157.3 \mathrm{mg} / \mathrm{dL}$ by $57.6 \%$. LDL-C was reduced below $1.8 \mathrm{mmol} / \mathrm{L}$ in $69.1 \%$ of patients overall, and for $64.7 \%$ and $77.4 \%$ of the HeFH and non-FH subgroups, respectively.

All patients who continued the current program experienced a significant decrease in LDL-C, 
Table 4. Effects of proprotein convertase subtilisin/kexin type 9 (PCSK9) inhibitors on low density lipoprotein-cholesterol (LDL-C) level ( 3 months vs. 1 year) therapy as added to statin and ezetymibe in familial hypercholesterolemia patients and baseline LDL-C $>160 \mathrm{mg} / \mathrm{dL}$ (> $4.1 \mathrm{mmol} / \mathrm{L})(\mathrm{n}=21)$.

\begin{tabular}{lccc}
\hline \multirow{2}{*}{ Lipid } & \multicolumn{2}{c}{ Mean (SD) } & P \\
\cline { 2 - 3 } & After 3 months & After 1 year \\
\hline LDL-C [mg/dL] (calculated) & $72.1(74.4)$ & $71.8(73.9)$ & 0.602 \\
LDL-C [mg/dL] (direct measurement) & $78.9(71.2)$ & $77.7(72.8)$ & 0.970 \\
Triglycerides [mg/dL] & $146.3(98.4)$ & $122.4(44.8)$ & 0.211 \\
HDL-C [mg/dL] & $45.9(10.1)$ & $45.2(9.5)$ & 0.904 \\
\hline
\end{tabular}

HDL-C — high density lipoprotein-cholesterol; SD — standard deviation

and $52 \%$ of patients even achieved the LDL-C goal. The greatest therapeutic effect was achieved 2 weeks following the inclusion of PCSK9 inhibitors, with a reduction of direct LDL-C by an average of $57.8(18.6) \%$ (median $56.9 \%$ [45.6-70.5\%]). After 3 months and 1 year a slight additional effect was also secured, achieving a decrease by an average of $65.5(16.3) \%$ (median $68.2 \%$ [53.8-79.4\%]) and 66.9 (18.7)\% (median 75.5\% [55.6-81.3\%]) respectively compared to baseline (Table 4). Median LDL-C values in subsequent determinations are presented in Figure 4. The rate of decrease in LDL-C levels seems to be consistent with clinical trials with evolocumab (FOURIER) and alirocumab (ODYSSEY OUTCOMES; ODYSSEY LONG TERM) $[9,10,25]$. In the FOURIER study, LDL-C decreased from the median baseline value of $92 \mathrm{mg} / \mathrm{dL}$ by an average of $57 \%$ after 4 weeks, and by $61 \%$ after 12 weeks [9]. In the ODYSSEY LONG TERM study, the difference between the alirocumab and placebo groups in the mean percentage change from baseline in calculated LDL-C level was $62 \%$ after 24 weeks [24]. The LDL-C levels qualifying patients for FOURIER, ODYSSEY OUTCOMES and ODYSSEY LONG TERM clinical trials were different than in the present study [9, 10, 25]. Very high-risk patients received treatment with PCSK9 inhibitors if the therapeutic target was not achieved, which, according to the then recommendations, was LDL-C $<70 \mathrm{mg} / \mathrm{dL}$ in secondary prevention. In the ODYSSEY FH I and FH II studies [14], the target LDL-C levels were $<70 \mathrm{mg} / \mathrm{dL}$ or $<100 \mathrm{mg} / \mathrm{dL}$, depending on the clinical profile of the volunteer (CVD present or absent).

The long-term safety and efficacy for evolocum$\mathrm{ab}$ in patients with $\mathrm{FH}$ were confirmed in another study where 194 severe $\mathrm{HeFH}$ and 106 with homozygous $\mathrm{FH}(\mathrm{HoFH})$, that included $14<18$ years of age patients were enrolled [26]. In this openlabel, single-arm study, patients on stable lipid-low- ering therapy were given subcutaneous evolocumab $420 \mathrm{mg}$ monthly or $420 \mathrm{mg}$ every 2 weeks if on lipoprotein apheresis. Mean change in LDL-C from baseline to week 12 was $-54.9 \%(-104.4 \mathrm{mg} / \mathrm{dL})$ in those with severe HeFHand-21.2\% (-59.8 mg/dL) in patients with $\mathrm{HoFH}$. Evolocumab was well tolerated over a median of 4.1 years.

Despite of careful implementation of the study design and further thorough analysis of the data the study remains observational. Another limitation was constituted by the small group of patients. This was the result of restrictive inclusion criteria for the therapeutic program.

The first Polish clinical observation demonstrates that the strong lipid-lowering effect of both PCSK9 inhibitors was confirmed in patients, while the LDL-C concentration threshold for inclusion in the therapy should correspond to the European recommendations.

\section{Conclusions}

Polish patients achieved a significant reduction in LDL-C concentrations (68\%) following treatment with PCSK9 inhibitors, which was stable over time. The treatment targets set out in the dyslipidaemia management guidelines were met with the addition of PCSK9 inhibitors in 52\% of patients with high baseline LDL-C on statin therapy (maximum or maximum tolerated) in combination with ezetimibe. Due to inclusion criteria, which are very restrictive and inadequate to the real clinical needs, the percentage of $\mathrm{FH}$ patients, who could benefit from treatment with PCSK9 inhibitors, is very limited. Assuming that there are approximately 150,000 people with FH in Poland, only $0.1 \%$ of this population could benefit from reimbursed treatment with PCSK9 inhibitors. At the National Center for Familial Hypercholesterolemia, there were 24 eligible patients $(7.6 \%$ of the probands and $4.7 \%$ of all $\mathrm{FH}$ 
patients-unpublished data of National Center for Familial Hypercholesterolemia in Gdansk).

\section{Conflict of interest: None declared}

\section{References}

1. World Health Organization. (2018). Noncommunicable diseases country profiles/2018. World Health Organization. https://apps.who. int/iris/handle/10665/274512 (License: CC BY-NC-SA 3.0 IGO).

2. Schmidt A, Pearce L, Wilkins J, et al. PCSK9 monoclonal antibodies for the primary and secondary prevention of cardiovascular disease. Cochrane Database Syst Rev. 2017; 4(4), doi: 10.1002/14651858.cd011748.pub2.

3. Mach F, Baigent C, Catapano AL, et al. 2019 ESC/EAS Guidelines for the management of dyslipidaemias: lipid modification to reduce cardiovascular risk. Eur Heart J. 2020; 41(1): 111-188, doi: 10.1093/eurheartj/ehz455, indexed in Pubmed: 31504418.

4. Pajak A, Szafraniec K, Polak M, et al. Prevalence of familial hypercholesterolemia: a meta-analysis of six large, observational, population-based studies in Poland. Arch Med Sci. 2016; 12(4): 687-696, doi: 10.5114/aoms.2016.59700, indexed in Pubmed: 27478447.

5. Chlebus K, Cybulska B, Gruchała M, et al. Prevalence, diagnosis, and treatment of familial hypercholesterolaemia in outpatient practices in Poland. Kardiol Pol. 2018; 76(6): 960-967, doi: 10.5603/KP.a2018.0053, indexed in Pubmed: 29399758.

6. Beheshti SO, Madsen CM, Varbo A, et al. Worldwide prevalence of familial hypercholesterolemia: meta-analyses of 11 million subjects. J Am Coll Cardiol. 2020; 75(20): 2553-2566, doi: 10.1016/j.jacc.2020.03.057, indexed in Pubmed: 32439005.

7. Hu P, Dharmayat KI, Stevens CAT, et al. Prevalence of familial hypercholesterolemia among the general population and patients with atherosclerotic cardiovascular disease: a systematic review and meta-analysis. Circulation. 2020; 141(22): 1742-1759, doi: 10.1161/ CIRCULATIONAHA.119.044795, indexed in Pubmed: 32468833.

8. Nordestgaard BG, Chapman MJ, Humphries SE, et al. Familial hypercholesterolaemia is underdiagnosed and undertreated in the general population: guidance for clinicians to prevent coronary heart disease: consensus statement of the European Atherosclerosis Society. Eur Heart J. 2013; 34(45): 3478-3490, doi: 10.1093/eurheartj/eht273, indexed in Pubmed: 23956253.

9. Sabatine MS, Giugliano RP, Keech AC, et al. Evolocumab and Clinical Outcomes in Patients with Cardiovascular Disease. N Engl J Med. 2017; 376(18): 1713-1722, doi: 10.1056/NEJMoa1615664, indexed in Pubmed: 28304224.

10. Schwartz G, Steg P, Szarek M, et al. Alirocumab and cardiovascular outcomes after acute coronary syndrome. N Engl J Med. 2018; 379(22): 2097-2107, doi: 10.1056/nejmoa1801174.

11. Cybulska B, Gaciong Z, Hoffman P, et al. [Severe hypercholesterolaemia--when to use the proprotein convertase subtilisinkexin type 9 protease inhibitors (PCSK9 inhibitors)? Polish Society of Cardiology experts' group statement]. Kardiol Pol. 2016; 74(4): 394-398, doi: 10.5603/KP.2016.0051, indexed in Pubmed: 27098076 .

12. Landmesser U, Chapman MJ, Stock JK, et al. 2017 Update of ESC/EAS Task Force on practical clinical guidance for proprotein convertase subtilisin/kexin type 9 inhibition in patients with atherosclerotic cardiovascular disease or in familial hypercholesterolaemia. Eur Heart J. 2018; 39(14): 1131-1143, doi: 10.1093/ eurheartj/ehx549, indexed in Pubmed: 29045644.
13. Wiegman A, Gidding SS, Watts GF, et al. Familial hypercholesterolaemia in children and adolescents: gaining decades of life by optimizing detection and treatment. Eur Heart J. 2015; 36(36): 2425-2437, doi: 10.1093/eurheartj/ehv157, indexed in Pubmed: 26009596.

14. Kastelein JJP, Ginsberg HN, Langslet G, et al. ODYSSEY FH I and FH II: 78 week results with alirocumab treatment in 735 patients with heterozygous familial hypercholesterolaemia. Eur Heart J. 2015; 36(43): 2996-3003, doi: 10.1093/eurheartj/ehv370, indexed in Pubmed: 26330422.

15. Ginsberg HN, Rader DJ, Raal FJ, et al. Efficacy and safety of alirocumab in patients with heterozygous familial hypercholesterolemia and LDL-C of $160 \mathrm{mg} / \mathrm{dl}$ or higher. Cardiovasc Drugs Ther. 2016; 30(5): 473-483, doi: 10.1007/s10557-016-6685-y, indexed in Pubmed: 27618825.

16. Hovingh GK, Raal FJ, Dent R, et al. Long-term safety, tolerability, and efficacy of evolocumab in patients with heterozygous familial hypercholesterolemia. J Clin Lipidol. 2017; 11(6): 1448-1457, doi: 10.1016/j.jacl.2017.09.003, indexed in Pubmed: 29066265.

17. Saborowski M, Dölle M, Manns MP, et al. Lipid-lowering therapy with PCSK9-inhibitors in the management of cardiovascular high-risk patients: Effectiveness, therapy adherence and safety in a real world cohort. Cardiol J. 2018; 25(1): 32-41, doi: 10.5603/ CJ.a2017.0137, indexed in Pubmed: 29168543.

18. Kohli M, Patel K, MacMahon Z, et al. Pro-protein subtilisin kexin-9 (PCSK9) inhibition in practice: lipid clinic experience in 2 contrasting UK centres. Int J Clin Pract. 2017; 71(11), doi: 10.1111/ijcp.13032, indexed in Pubmed: 28994502.

19. Stoekenbroek RM, Hartgers ML, Rutte R, et al. PCSK9 inhibitors in clinical practice: Delivering on the promise? Atherosclerosis. 2018; 270: 205-210, doi: 10.1016/j.atherosclerosis.2017.11.027, indexed in Pubmed: 29254691.

20. Rallidis LS, Skoumas I, Liberopoulos EN, et al. PCSK9 inhibitors in clinical practice: Novel directions and new experiences. Hellenic J Cardiol. 2020; 61(4): 241-245, doi: 10.1016/j. hjc.2019.10.003, indexed in Pubmed: 31783124.

21. Galema-Boers AMH, Lenzen MJ, Sijbrands EJ, et al. Proprotein convertase subtilisin/kexin 9 inhibition in patients with familial hypercholesterolemia: Initial clinical experience. J Clin Lipidol. 2017; 11(3): 674-681, doi: 10.1016/j.jacl.2017.02.014, indexed in Pubmed: 28506389.

22. Kaufman TM, Warden BA, Minnier J, et al. Application of PCSK9 Inhibitors in Practice. Circ Res. 2019; 124(1): 32-37, doi: 10.1161/CIRCRESAHA.118.314191, indexed in Pubmed: 30605414.

23. Zafrir B, Jubran A. Lipid-lowering therapy with PCSK9-inhibitors in the real-world setting: Two-year experience of a regional lipid clinic. Cardiovasc Ther. 2018; 36(5): e12439, doi: 10.1111/17555922.12439, indexed in Pubmed: 29863817.

24. Gaudet D, López-Sendón J, Averna M, et al. Efficacy and safety of alirocumab in a real-life setting in patients with or without familial hypercholesterolemia: the odyssey apprise study. J Am Coll Cardiol. 2020; 75(11): 1958, doi: 10.1016/s0735-1097(20)32585-7.

25. Robinson JG, Farnier M, Krempf M, et al. Efficacy and safety of alirocumab in reducing lipids and cardiovascular events. $\mathrm{N}$ Engl J Med. 2015; 372(16): 1489-1499, doi: 10.1056/NEJMoa1501031, indexed in Pubmed: 25773378.

26. Santos RD, Stein EA, Hovingh GK, et al. Long-Term evolocumab in patients with familial hypercholesterolemia. J Am Coll Cardiol. 2020; 75(6): 565-574, doi: 10.1016/j.jacc.2019.12.020, indexed in Pubmed: 32057369. 